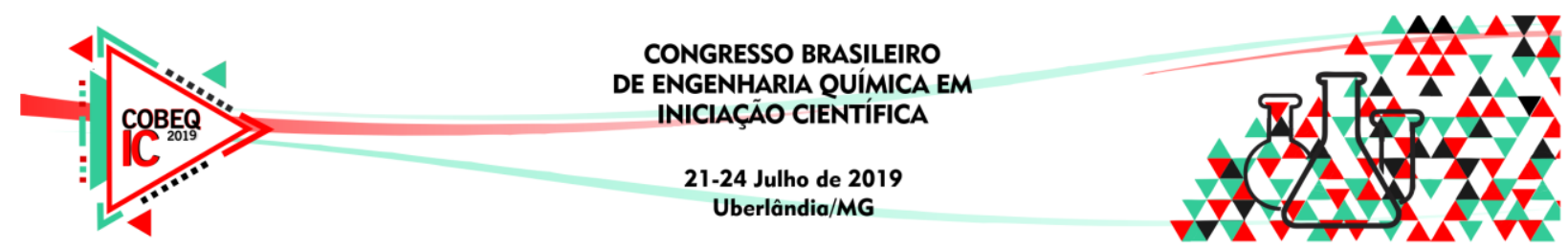

\title{
ANÁLISE DA CINÉTICA DE SECAGEM E DO ENCOLHIMENTO DAS CASCAS DE CACAU
}

\author{
G.L. CARREIRO JUNIOR ${ }^{1}$, A.O.V. MARTINS ${ }^{1}$, J.S.SANTOS JUNIOR ${ }^{1}$, A.B.S. COSTA ${ }^{1}$, \\ R.C de SOUSA ${ }^{1 *}$ \\ Universidade Federal do Espírito Santo, Departamento de Engenharia Rural \\ Centro de Ciências Agrárias e Engenharias - Engenharia Química \\ *e-mail: robson.sousa@ufes.br
}

\begin{abstract}
RESUMO - Buscando contribuir com estudos relacionados ao aproveitamento de resíduos agrícolas em biomassa, o presente trabalho teve como objetivo analisar, utilizando estufa de convecção forçada, a cinética de secagem das cascas de cacau e também o encolhimento gerado pelo processo quando foi trabalhado em quatro diferentes temperaturas: $50^{\circ} \mathrm{C}, 60^{\circ} \mathrm{C}, 70^{\circ} \mathrm{C}$ e $80^{\circ} \mathrm{C}$. A quantificação das dimensões do material foi realizada com o auxílio do software ImageJ e, a partir dos dados coletados, foram produzidos gráficos do grau de encolhimento em função do adimensional de umidade para cada temperatura avaliada. Os resultados mostraram que em temperaturas mais altas a umidade de equilíbrio foi alcançada em menor tempo. Quanto ao comportamento do encolhimento da casca, os dados apontaram que esse material, com relação ao volume de água perdido, apresenta uma relação que se aproxima da linear.
\end{abstract}

\section{INTRODUÇÃO}

O cacau é um fruto de grande importância mundial, pois além de ser a principal matéria prima na produção de chocolate, possui também aplicações em produtos fármacos e cosméticos, decorrente das vitaminas e sais minerais que estão presentes em suas sementes e polpas (LIMA, 2010).

O processamento e a industrialização do cacau no Brasil geram quantidades apreciáveis de diversos subprodutos e resíduos potencialmente exploráveis. Nas propriedades agrícolas onde realiza-se o primeiro processamento do fruto, são geradas toneladas de resíduos que correspondem às suas cascas. Cerca de 6 toneladas, em média, deste material fresco são produzidas anualmente por hectare e quando dispostas na própria lavoura, favorecem a proliferação de doenças como a vassoura-de-bruxa, além de liberarem odores fétidos devido à decomposição. Diante disso, uma forma de realizar o beneficiamento do respectivo resíduo é a partir da secagem, pois inibi a ação microbiana e agrega características importantes ao produto como o aumento da vida útil, maior facilidade no transporte e armazenamento (SODRÉ et al., 2012; BATISTA, 2014; GALDINO et al., 2016).

Porém, a secagem pode causar deteriorações na estrutura física do material diretamente relacionada a redução das dimensões, ou seja, o encolhimento do material. A desidratação 


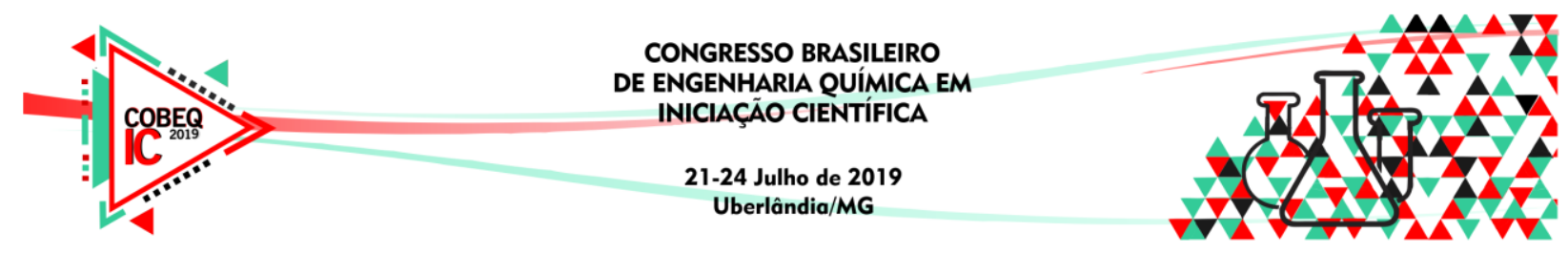

gerada em materiais biológicos durante este processo reduz os espaços intercelulares, fazendo com que os espaços anteriormente ocupados pela água sejam agora completados pela matéria seca, modificando seu volume. Além de alterar as características de permeabilidade de qualquer solvente, decorrente da crosta formada, deixando o material mais instável e quebradiço, alterando a massa específica e as propriedades mecânicas, ambos efeitos indesejáveis para qualquer produto final (ARRIECHE, 2003; ARRIECHE E SARTORI 2009; JÚNIOR et al., 2000).

Entendendo-se a importância de se desenvolver alternativas viáveis para o tratamento dos resíduos obtidos do cacau, que são em sua grande quantidade descartada atualmente no Brasil, o presente trabalho tem por objetivo analisar a secagem e a dinâmica de encolhimento da casca do cacau em quatro diferentes níveis de temperatura, a fim de verificar influência da temperatura nas mudanças estruturais das amostras.

\section{MATERIAIS E MÉTODOS}

\subsection{Material}

A matéria-prima utilizada no desenvolvimento deste estudo foi a casca de cacau da espécie Criollo, obtida de pequenos agricultores localizados do município de Conceição do Castelo, região Sul do Estado do Espírito Santo.

\subsection{Ensaios de secagem}

Os experimentos de secagem das cascas do cacau foram realizados na Universidade Federal do Espírito Santo (UFES) no Campus de Alegre, utilizando estufa de convecção forçada.

Primeiramente, as amostras foram cortadas em dimensões de $1 \times 1 \mathrm{~cm}$. Após o prétratamento, ajustou-se a temperatura desejada na estufa e esperou-se que o estado estacionário fosse alcançado.

Assim que a temperatura na estufa se manteve constante com o tempo, as amostras foram inseridas na mesma e, então, iniciou-se os ensaios experimentais medindo, de tempos em tempos, a massa das amostras em uma balança analítica, até que se fosse atingido a massa de equilíbrio. Em seguida, as mesmas foram colocadas em uma segunda estufa a temperatura de $105^{\circ} \mathrm{C}$ por um período de $24 \mathrm{~h}$, para a determinação da massa seca. Os experimentos foram desenvolvidos em triplicata nas temperaturas de $50^{\circ} \mathrm{C}, 60^{\circ} \mathrm{C}, 70^{\circ} \mathrm{C}$ e $80^{\circ} \mathrm{C}$. Com as informações da massa seca e das massas das amostras durante o experimento, determinou-se a umidade em base seca e o adimensional de umidade para a construção dos gráficos das curvas de cinética de secagem. 


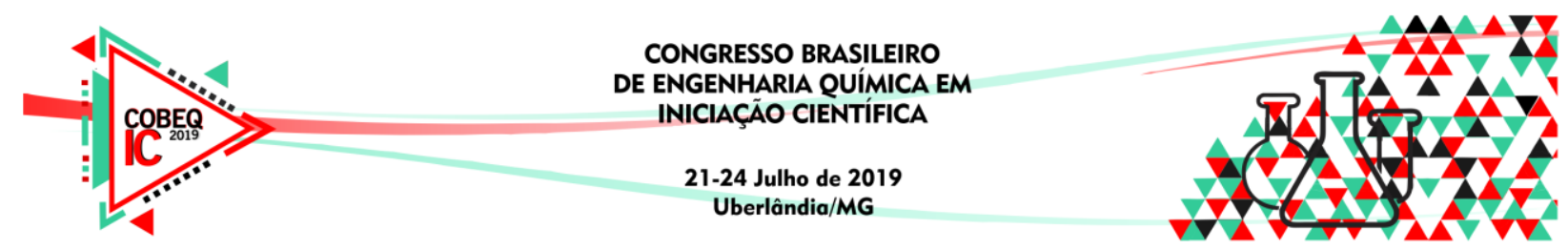

\subsubsection{Encolhimento}

Para quantificar o encolhimento das cascas de cacau submetidas à secagem nas diferentes temperaturas, foi analisada a variação do comprimento, perímetro projetado, espessura, área projetada e volume com o auxílio do software gratuito Image J e uma câmera digital de 12MP.

Durante os ensaios de secagem, após a pesagem das amostras na balança analítica, as mesmas eram colocadas em um fundo branco e realizava-se a captura das imagens. Cada amostra foi fotografada em duas etapas, a primeira referia-se a foto com a parte superior da amostra (para a visualização das dimensões comprimento, perímetro projetado e área projetada) e a segunda correspondia a foto da lateral da amostra (para a espessura), conforme pode ser visualizado na figura 1.

Figura 1 - Representação das diferentes medidas realizadas em uma amostra de cascas de cacau para os cálculos de dimensões características, em que a foto (a) refere-se à medida realizada na lateral da amostra e a (b) corresponde à medida realizada na parte superior da mesma.
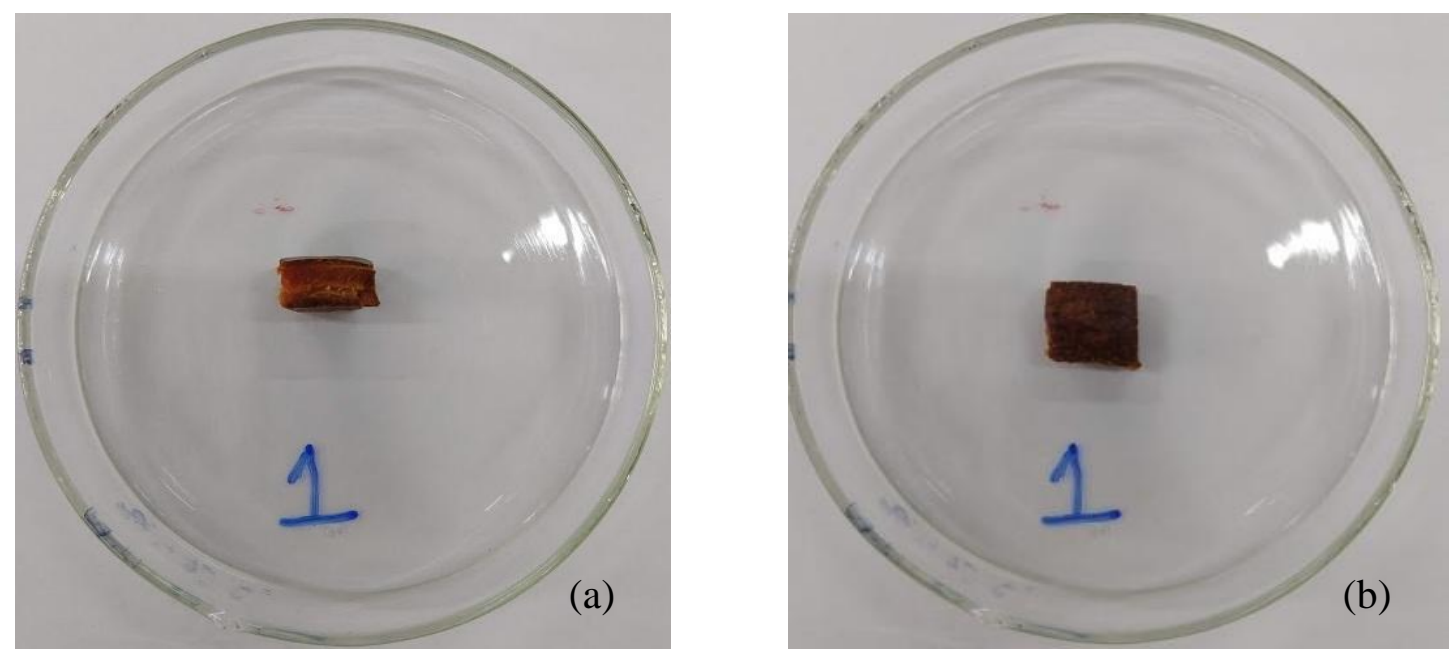

Antes que fossem analisadas as dimensões características das cascas de cacau no software, primeiramente, foi necessário determinar um comprimento padrão nas imagens, para padronização das medidas realizadas. Neste trabalho correspondeu ao diâmetro da placa de Petri, que era de $10 \mathrm{~cm}$. Em seguida, então, realizava-se a compilação das medidas e, posteriormente, calculava-se o grau de encolhimento de cada dimensão característica de acordo com a Equação 1:

$(\mathrm{No}-\mathrm{N}) / \mathrm{No}$

Onde "No" é a medida inicial e "N" é a atual. 


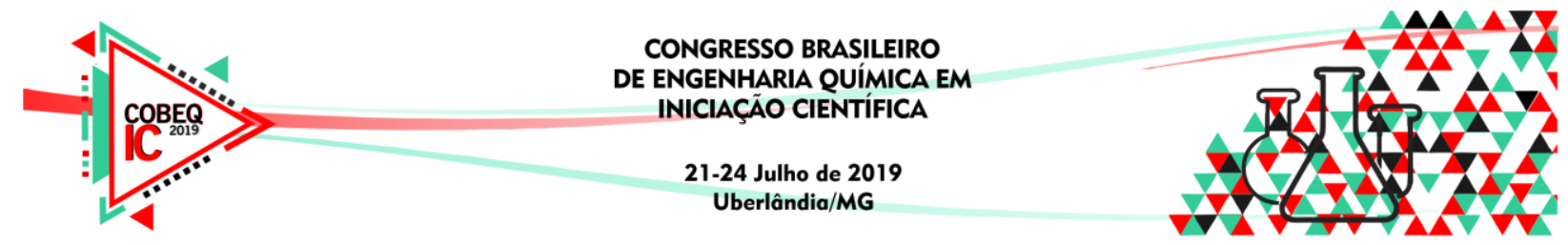

Como os ensaios de secagem foram realizados em triplicata, a mesma quantidade de medidas para comprimento, área projetada, perímetro projetado e volume foram obtidas para as quatro temperaturas trabalhadas. Em seguida foi calculado a média e o desvio padrão para cada condição e, a partir disso, plotou-se os gráficos do grau de encolhimento em função do adimensional de umidade para as cinco grandezas.

\section{RESULTADOS E DISCUSSÕES}

\subsection{Cinética de secagem}

Na Figura 2 são apresentadas as curvas do adimensional de umidade em função do tempo para as cascas de cacau nas temperaturas de 50 e $80^{\circ} \mathrm{C}$. Como o efeito da temperatura foi o mesmo para todos os ensaios experimentais empregados nas secagens, adotou-se apresentar as condições extremas trabalhadas.

A partir dos resultados obtidos pode-se verificar que o aumento da temperatura na estufa acelerou o processo de secagem, reduzindo o tempo em que as amostras alcançaram o equilíbrio, de 310 minutos para 220 minutos, respectivamente a $50^{\circ} \mathrm{C}$ e $80^{\circ} \mathrm{C}$. Estes resultados mostraram que o aumento da temperatura promoveu um maior fornecimento de energia para a amostra, aumentando a taxa de evaporação da água contida na casca de cacau e, por consequência, favorecendo uma secagem mais rápida. (GALDINO et al., 2016, BORGES et al., 2008, QUEROZ; NEBRA, 2001).

Figura 2 - Curvas do adimensional de umidade em função do tempo para as amostras submetidas às temperaturas de (a) $50^{\circ} \mathrm{Ce}$ (b) $80^{\circ} \mathrm{C}$.
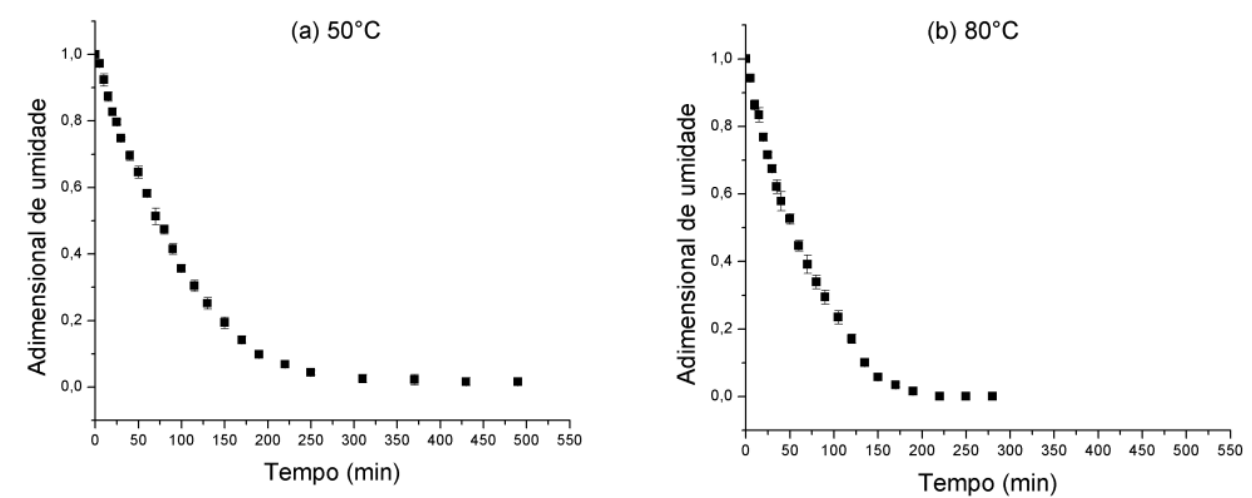

\subsection{Encolhimento}

Na Figura 3 serão apresentadas as curvas do grau de encolhimento do material em função do adimensional de umidade. Seguindo a mesma linha de raciocínio empregada anteriormente, só será apresentada a condição de $80^{\circ} \mathrm{C}$, visto que nos outros experimentos o comportamento foi análogo. 


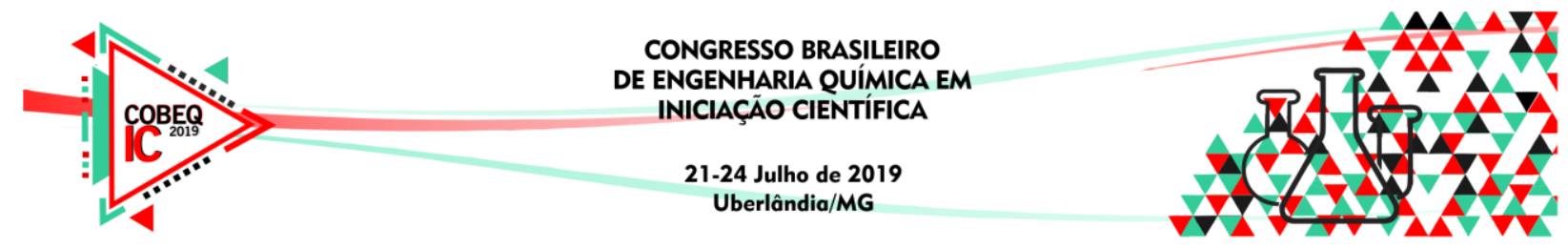

Os gráficos devem ser lidos da esquerda para a direita, começando na umidade adimensional com valor unitário e, consequentemente, com grau de encolhimento zero, até a umidade zero e, consequentemente, grau de encolhimento máximo obtido. A primeira informação que pode ser interpretada é que as amostras tiveram um encolhimento muito significativo, chegando a $70 \%$ em termos de volume.

Nesta figura também pode-se observar que o encolhimento teve um comportamento próximo ao linear, quando relacionado com a perda de umidade. Logo, os dados apontam que este material segue um comportamento de secagem uniforme, no qual o encolhimento das cascas é diretamente proporcional ao volume de água perdido durante a corrida de secagem (SUZUKY et al., 1976).

Figura 3 - Curvas do encolhimento da casca de cacau em função do adimensional de umidade para o comprimento (a), perímetro (b), área (c), espessura (d) e volume (e).
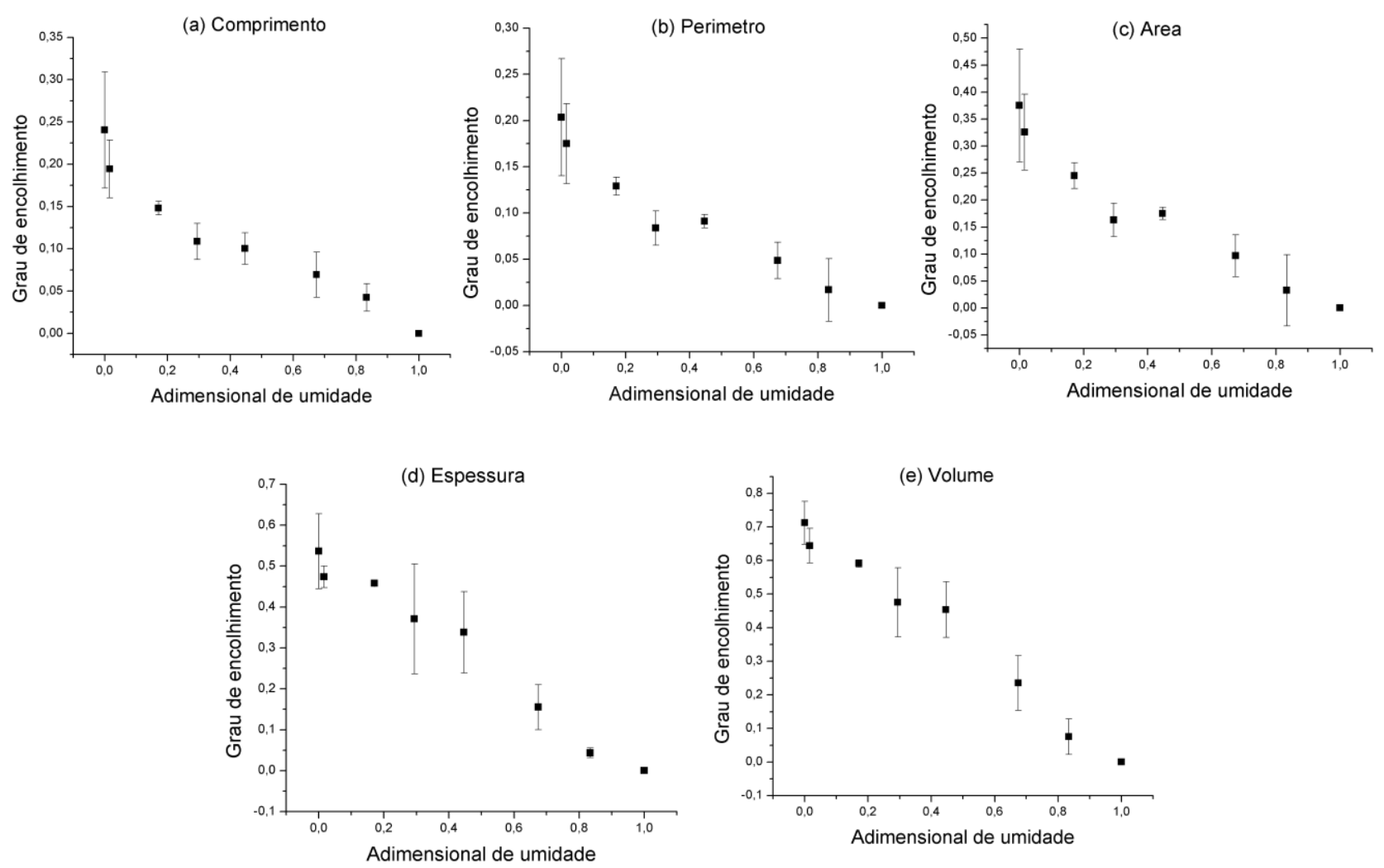

\section{CONCLUSÃO}

Os resultados mostraram que as amostras expostas às menores temperaturas tiveram o maior tempo de processo, em relação às expostas às maiores temperaturas, logo, a secagem realizada a $80^{\circ} \mathrm{C}$ alcançou em menor tempo a umidade de equilíbrio. 


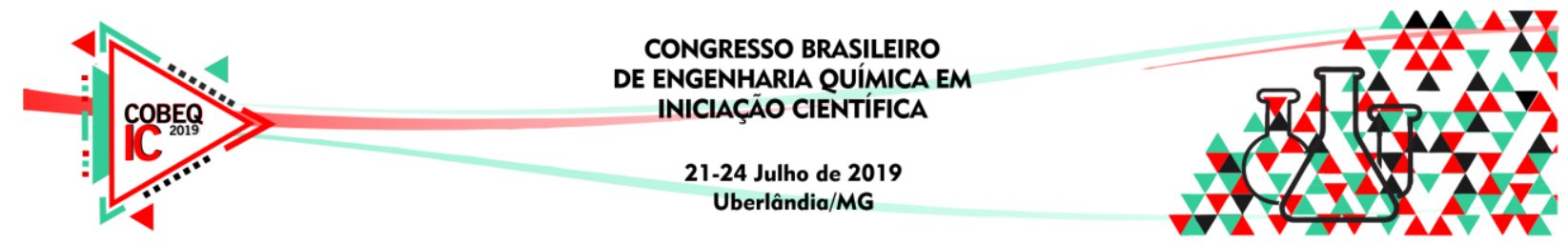

Dos resultados obtidos para o encolhimento das cascas de cacau, verificou-se que esse material possui uma relação linear entre o encolhimento e a perda de umidade. Isso implica que se pode considerar que a casca do cacau segue o modelo secagem uniforme.

\section{REFERÊNCIAS}

AFONSO JÚNIOR, P. C. et al. Estudo do encolhimento do fruto de café durante o processo de secagem. In: SIMPÓSIO DE PESQUISA DO CAFÉS DO BRASIL, 1., 2000, Poços de Caldas, Mg. Anais do I Simpósio de Pesquisa dos Cafés do Brasil.

Belo Horizonte: Embrapa Café, 2000. p. 1138 - 1141.

ARRIECHE, L S. Evolução da forma e encolhimento de um sistema gel durante a secagem por convecção forçada. 2003. 136 f. Dissertação (Mestrado) - Curso de Engenharia Química, Programa de Pós-graduação em Engenharia Química, Universidade Federal de São Carlos, São Carlos, 2003.

BORGES, S. V.; MANCINI, M. C.; CORRÊA, J. L. G.; NASCIMENTO D. A. Secagem de fatias de abóboras (Cucurbita moschata, L.) por convecção natural e forçada, Ciência e Tecnologia de Alimentos, Vol. 28, p. 245-251.

GALDINO, C. M.; NASCIMENTO, B. P.; SANTOS, M. M. N.; MENEGUELO, A. P.; ARRIECHE, L. S. (2016), Estudo da cinética de secagem das cascas de cacau, Anais do XXI Congresso Brasileiro de Engenharia Químcia, Fortaleza - CE.

LIMA, U. Matéria prima dos alimentos. 2.ed. Sao Paulo: Blucher, 2010 p. 238-331.

QUEIROZ, M. R.; NEBRA, S. A. Theoretical and experimental analysis of drying kinetics of bananas. Journal of Food Engineering, v. 47, n. 2, p. 127-132, 2001.

SODRÉ, G.A.; VENTURINI, M.T.; RIBEIRO, D.O.; MARROCOS, P.C.L. Extrato da casca do fruto do cacaueiro como fertilizante potássico no crescimento de mudas de cacaueiro. Ver. Bras. Frutic., v.34, n. 2, p. 881-887, 2012. 